\title{
Physico-Chemical and Microbial Analysis of Drinking Water of Four Springs of Danyore Gilgit Baltistan Pakistan
}

\author{
Samina Kanwal ${ }^{1}$, Saif-Ud-Din ${ }^{3 *}$, Khalil Ahmed ${ }^{2}$, Maisoor Ahmed Nafees ${ }^{2}$, Sheheryar \\ Anwar $^{3}$
}

\begin{abstract}
${ }^{1}$ Elysian Higher Secondary School Chinar Bagh Gilgit, Gilgit-Baltistan, Pakistan.
${ }^{2}$ Department of Biological Sciences, Karakoram International University Gilgit, Gilgit-Baltistan, Pakistan.

${ }^{3}$ Department of Environmental Sciences, Karakoram International University Gilgit, Gilgit-Baltistan, Pakistan.
\end{abstract}

\begin{abstract}
Drinking water of good quality is essential for human physiology whose continual existence depends on the availability of water and any sort of contamination in water which is above the standard limits set by international water regulating agencies can lead to water related diseases. So, the present investigation was conducted to determine the physico-chemical and bacteriological contents of four springs i.e.Heshi spring 1, Heshi spring 2, Kitaab Roong, and Kooti spring and its distribution system such as water reservoir inlet, outlet, mid and end point of distribution systems, junction where it merge with glacier water. The temperature was in a range of $13^{\circ} \mathrm{C}-22^{\circ} \mathrm{C}$. The turbidity of water samples fluctuate from 0.02NTU-1.99NTU. The $\mathrm{pH}$ value was in a range of 6.2-7.1. Electrical conductivity range of minimum $122 \mu \mathrm{S} / \mathrm{cm}$ to a maximum of $600 \mu \mathrm{S} / \mathrm{cm}$. The TDS of all water samples ranging from minimum of 164$513 \mathrm{mg} / \mathrm{l}$. The amount of reactive ortho phosphate was in a range of $26 \mathrm{mg} / \mathrm{l}$ to $59 \mathrm{mg} / \mathrm{L}$. The amount of total phosphorous was in a range of minimum $23 \mathrm{~m} / \mathrm{L}$ to maximum of $120 \mathrm{mg} / \mathrm{L}$. The total bacterial count was in a range of $11 \mathrm{CFU} / 100 \mathrm{ml}$ to $83 \mathrm{CFU} / 100 \mathrm{ml}$.The findings showed there should be comprehensive standardization of drinking water of Danyore village according to guidelines of WHO water quality standards and make it safe for human consumption.
\end{abstract}

Keywords - Drinking water, springs, Heshi, Kitaab Roong, Kooti, UV Spectrophotometer, Membrane Filtration Technique, Pour Plate Technique.

\section{INTRODUCTION}

Geographical location dominates the weather conditions of Gilgit-Baltistan, it's a valley in mountainous neighborhood southwest of Karakorum Range region. Winter is the dominant season of this orbit and prevails in the region for eight to nine months a year. Gilgit lacks significant rainfall averaging $120 \quad-140$ millimeters annually. While the summertime season is short and warm the piercing sun-ray raise the mercury up to 40 ${ }^{\circ} \mathrm{C}[1]$.

Water covers $71 \%$ of earth's surface on the off chance that we gage the level of oceans and seas, it turns out to be $96.5 \%$ of planet earth's water. The second and third supplies of water are ground water and ice sheets each contributing $1.7 \%$ to add up to globe. New water makes a moment division, which is $2.5 \%$ of earth's water and $99 \%$ of all crisp water supplies are found in ice sheets. About a fourth of total populace depends on these water sources [2].

One to a few liters of water requires each day to sidestep for dehydration. It is a basic asset to enhance sustenance security, horticulture, condition and biodiversity [3].

Water becomes obviously dirtied when contaminated by anthropogenic exercises. Water contamination has turned into a noteworthy issue overall in view of being cause for more than 14000 passings every day and a few sicknesses [4].

When we consider water contamination, we normally imagine sewage or industrial effluents spilling out of a release pipe and some lethal chemicals acquaint in with water because of human exercises, yet there are regular toxicants that threat as well. It additionally satisfies every single fundamental necessity of living people like their development, upkeep of body and to play out all life supporting exercises [5];[6].

Over the globe, water bodies are essential for survival. A large portion of the water supplies are in the form of streams. Unfortunately, for the most part streams are defiled because of a few human induced components, which dilute and dissolve waste into them. With the expanding of population, urbanization and industrialization, the earth is impressively dirtied even in the developing nations [7].

Massive shortage of edible water is felt in developing nations where requisites of public supply of drinking water is poor owing partially to the lack of enough 
financial obligations towards existing infrastructure. People in rural communities often route to other options for dependable source of water for drinking and to fulfil other domestic needs [8].

The bacteriological contamination of water is major problem in developing countries. According to WHO water pollution in developing countries, like Pakistan estimates about $80 \%$ carried out by domestic wastes. Studies have revealed that E.coli and Enterococci are widely used water quality indicators of fresh water sources, Enterococci particularly is more significant indicator of water quality. The presence of Enterococci in water show fecal contamination because of their loads in faeces and subject water is not considered as safe to drink [8].

\section{MATERIALS AND METHODS}

Study Area

The study was conducted on selected springs of Danyore Nallah "Manu Gah" of district Gilgit. Four springs namely Heshi Spring 1, Kitaab Rong Spring, Heshi Spring 2, Kooti Spring were selected for study they were present at $2637 \mathrm{~m}, 2606 \mathrm{~m}, 2607 \mathrm{~m}, 1990 \mathrm{~m}$ above sea level respectively. These springs merge with glacier water on its way down to valley and provide drinking water for Danyore village. Samples were collected from the eyes of above mentioned springs, from the junction where the spring water mix with glacier water stream, inlet and outlet of water reservoir and from two different taps of Danyore village.

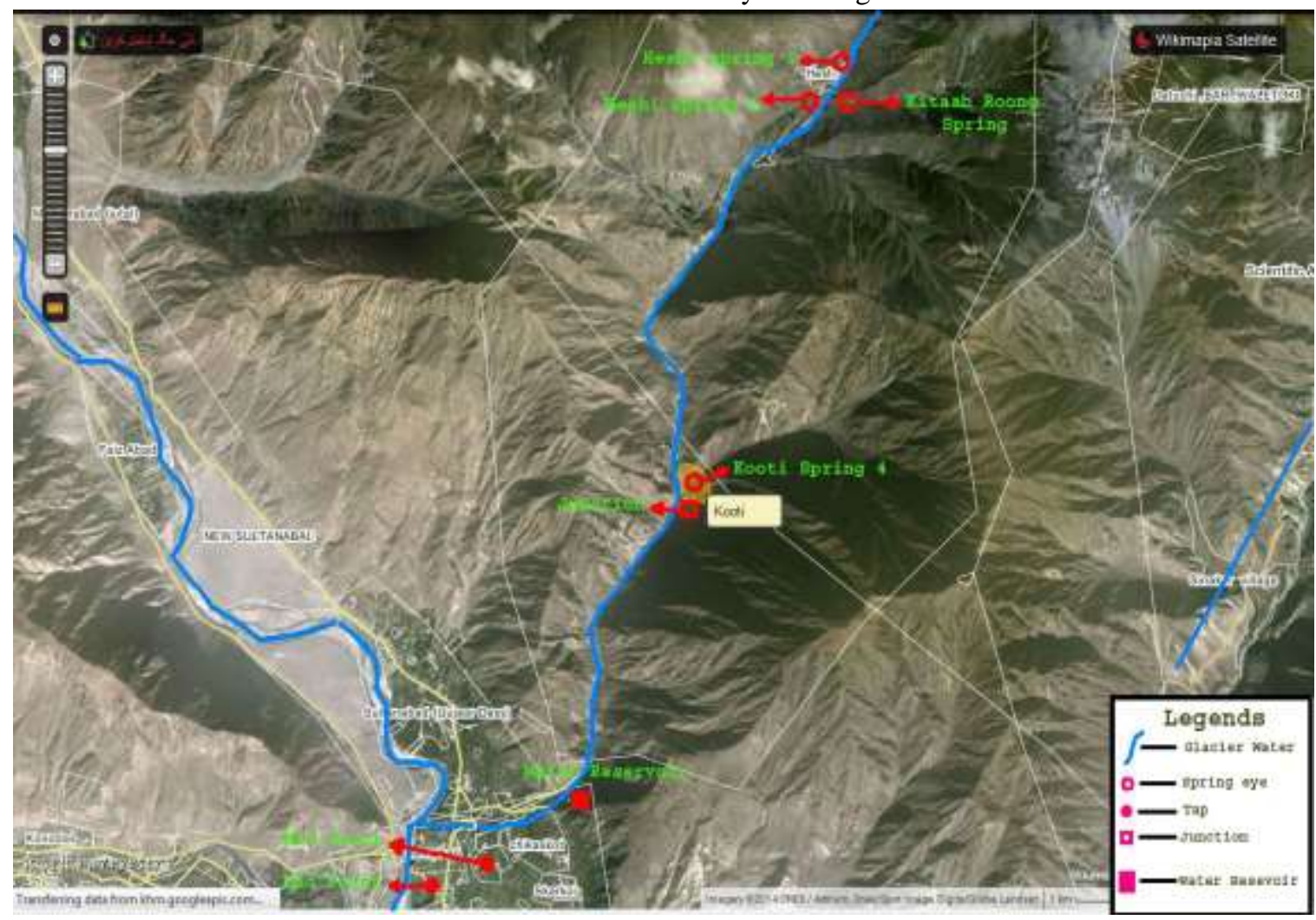

Fig.1: Map of sampling sites

\section{Sampling Design}

Eighteen samples were collected from four springs of Danyore Nallah in the month of March and April four samples from each spring eye, one sample from junction wherespring water mix with glacier water, one sample from inlet and one from outlet of water reservoir, and two samples from distribution were collected for physicochemical and microbial analysis. Temperature and elevation were measured on the spot using mercury glass in centigrade thermometer and GPS respectively and readings were noted down in data sheet. Samples for microbial assessment were collected in $1000 \mathrm{ml}$ sterilized bottles by autoclaved from $20-30 \mathrm{~cm}$ deep to avoid to let air bubbles as much as possible avoiding touching the bottom and polluting the samples with hands to prevent any contamination. Samples for physico-chemical assessment were collected in polythene bottles, prior sample collection rinsed thoroughly for at least three times. Each water sample was stored in separate plastic bottle with proper labeling. The watersamples were taken to (EPA certified water quality laboratory in Department of Biological Sciences Karakorum International University Gilgit Baltistan, pakistan) for further analysis. $\mathrm{pH}$ of the water samples was done in laboratory using Digital pH meter (AD 1020, ADWA). Prior measurement of $\mathrm{pH}$, meter was calibrated with standard buffers of $\mathrm{pH}$ 4.0, 7.0 and 9.0. Turbidity was measured using Electronic Turbidimeter (TB1, VELF SCIENTIFICA) and expressed 
in terms of NTU. Conductivity of water samples was measured using Digital Conductivity Meter (AD3000, ADWA)and stated in terms if $\mu \mathrm{S} / \mathrm{cm}$. Total dissolved solids of the samples were obtained using Digital Conductivity Meter (AD3000, ADWA) and stated in $\mathrm{mg} / \mathrm{l}$.

UV Spectrophotometer (UV 23000II, model) was used to determine the concentration of Total phosphorus and reactive Orthophosphate by National research council for Ecosystem Study Verbania Pallanza ItalyWater chemistry laboratory analytical methods [9].

Bacteria were isolated through Membrane Filtration Technique by filtering $100 \mathrm{ml}$ water through Cellulose Nitrate membrane Filter (0.45micro meter). Chromogenic X-Glu agar (Biolife, Itley), Slanetz and Bartley agar (Biolife, Itley) and Bile Esculine Azide agar BEA (Biokar diagnostics) were prepared following the instructions of the product and placed the filtered membrane on Chromogenic Agar for E. coli and Slanetz Bartley agar for Enterococci. Later on the colonies of Enterococci were confirmed by culturing on Bile Esculine Azide Agar.
Total Bacterial Count was done by Pour Plate Technique by culturing on Yeast Extract agar (BIOM lab, Malaysia). Yeast Extract agar was prepared by following the instructions labeled on the product. The procedure for bacteriological analysis was followed as per standard methods for the examination of water and waste water [10].

\section{Statistical Analysis}

The observed data was analysed Descriptive statistic and correlation with MS Excel 2007 and Statistix 8.1 software package. The multiple dimensional scaling of various parameters was analyzed using Statica software package (Statsoft Inc. 5.5).

\section{RESULTS AND DISCUSSIONS} Correlation for Physico-Chemical Parameters

For all four springs eye, correlation of coefficient among four different springs eye included in the study are given in Table 1. It was found that there were no positive significant correlation among the variables yet a negative correlation was observed in a variable such as between Total Phosphorous and TDS (r=-0.959).

Table.1: Correlation for Physico-Chemical parameter of springs eye at $p<.050$

\begin{tabular}{|l|l|l|l|l|l|l|}
\hline & TURBIDIT & PH & TDS & REACT_OP & TOT_P & EC \\
\hline TURBIDIT & 1 & & & & & \\
\hline PH & 0.8787 & 1 & & & & \\
\hline TDS & $\mathrm{p}=.121$ & & & & & \\
\hline & 0.0806 & 0.4957 & 1 & & & \\
\hline REACT_OP & $\mathrm{p}=.919$ & $\mathrm{p}=.504$ & & & & \\
\hline & $\mathrm{p}=.688$ & -0.6551 & -0.5049 & 1 & & \\
\hline TOT_P & -0.0584 & $\mathrm{p}=.345$ & $\mathrm{p}=.495$ & & & \\
\hline & $\mathrm{p}=.942$ & -0.5201 & $\mathbf{- 0 . 9 5 9 6}$ & 0.7094 & 1 & \\
\hline EC & -0.1451 & $\mathrm{p}=.480$ & $\mathbf{p}=. \mathbf{0 4 0}$ & $\mathrm{p}=.291$ & & 1 \\
\hline & $\mathrm{p}=.855$ & -0.1676 & 0.3559 & 0.6199 & -0.087 & \\
\hline
\end{tabular}

* Marked correlations are significant at $\mathrm{p}<0.05$

Total Dissolved Solids (TDS), Reactive Orthophosphate (REACT_OP), and Total Phosphorous (TP).

Physico-chemical parameters of springs eye by Multidimensional Scaling

The physico-chemical parameters of four spring's eye were based on multidimensional scaling where clear variations among various sources were observed. Kooti spring showed clear difference as compared to other three spring's eye. The main reason of this difference is due to the highest content TDS $(513 \mathrm{mg} / \mathrm{l})$ this finding is not in accordance with the WHO standard $(<500 \mathrm{mg} / \mathrm{l})$. However other spring eye sources showed less than this range. 
3D Scatterplot of Physico-Chemcial Analysis

TOT_Phosphorus vs. TDS vs. PH

(Casewise deletion of missing data)

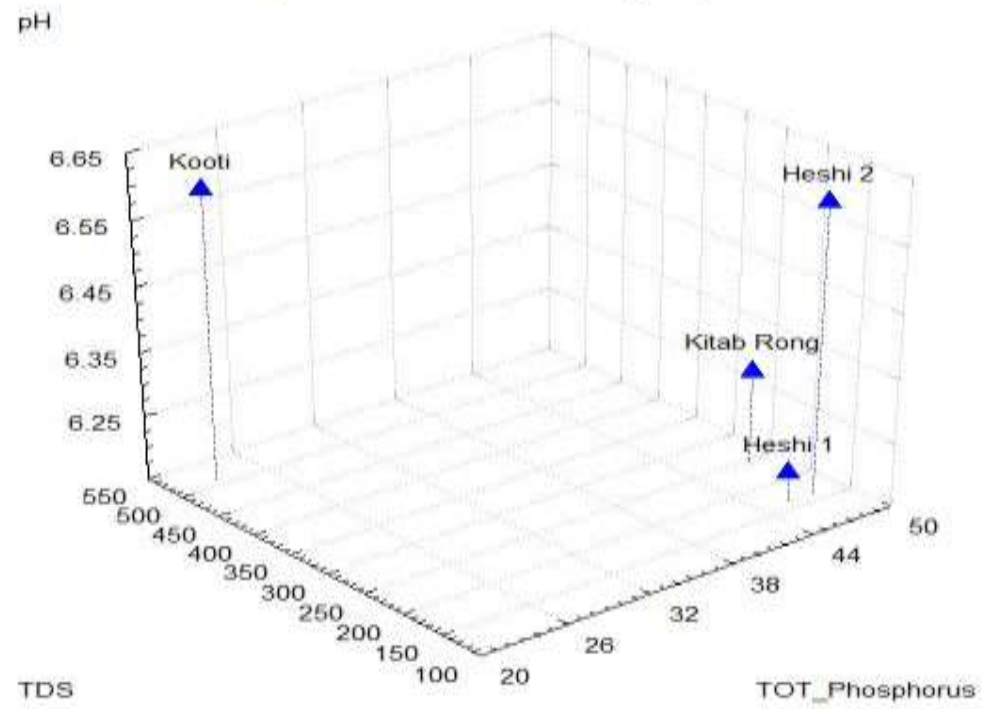

Fig.2: Three dimensional (3D) views of Physico-Chemical parameters of four spring's eye by multidimensional scaling

\section{Correlation of Microbial Parameters}

For all four springs eye, correlation of coefficient among four different springs eye included in the study are given in Table II. It was obtained that there were significant correlation among the variables. Like Heshi spring 1 and
Kitaab Roong spring have significant correlation. Similarly Heshi spring 2 and Kitaab Roong and Kooti spring and Heshi spring 2 showed significant correlation $(\mathrm{r}=0.999)$.

Table.2: Correlation for Microbial parameter of springs eye at $p<.050$

\begin{tabular}{|l|l|l|l|l|}
\hline & Heshi spring 1 & Kitaab Roong spring & Heshi spring 2 & Kooti spring \\
\hline Heshi spring 1 & 1 & & & \\
\hline $\begin{array}{l}\text { Kitaab Roong } \\
\text { spring }\end{array}$ & $\mathbf{0 . 9 9 9}$ & 1.000 & & \\
\hline Heshi spring 2 & 0.997 & $\mathbf{0 . 9 9 9}$ & 1.000 & \\
\hline Kooti spring & 0.994 & 0.998 & $\mathbf{0 . 9 9 9 6}$ & 1.000 \\
\hline
\end{tabular}

Microbiological parameters of springs eye by Multidimensional Scaling

The microbiological parameters of four spring's eye were based on multidimensional scaling where clear variations among various sources were observed. Kooti spring showed clear difference as compared to other three spring's eye. The main reason of this difference is due to the highest level of contamination this finding is not in accordance with the WHO standard (0CFU/100ml). However other spring eye sources showed less than this range. 
Scatterplot (3D) microbial contamination in spring"s eye

E.COLIVS. ENTERROCOCCI VB. TBC

TEC:

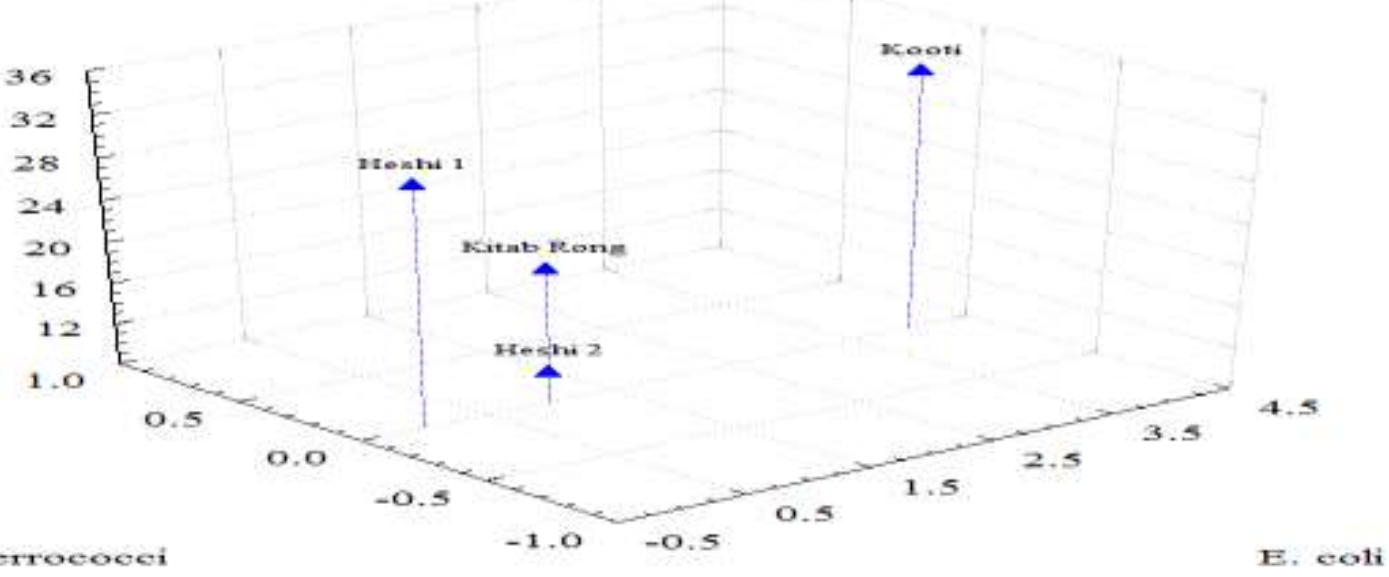

Fig.3: Three dimensional (3D) view of microbial parameters (E.coli vs. Enterococci vs. TBC) of four spring's eye by multidimensional scaling

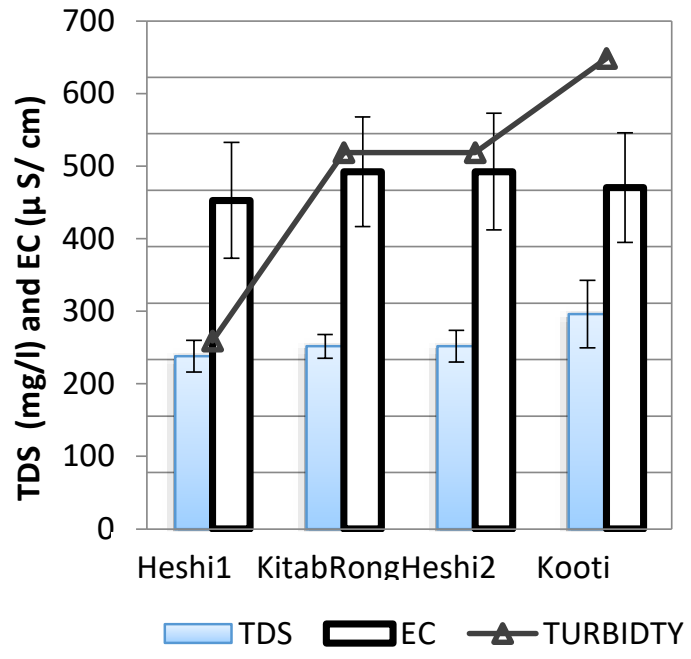

0.955

0.95

0.945

0.94

0.935

0.93

0.925

0.92

0.915

ก.91
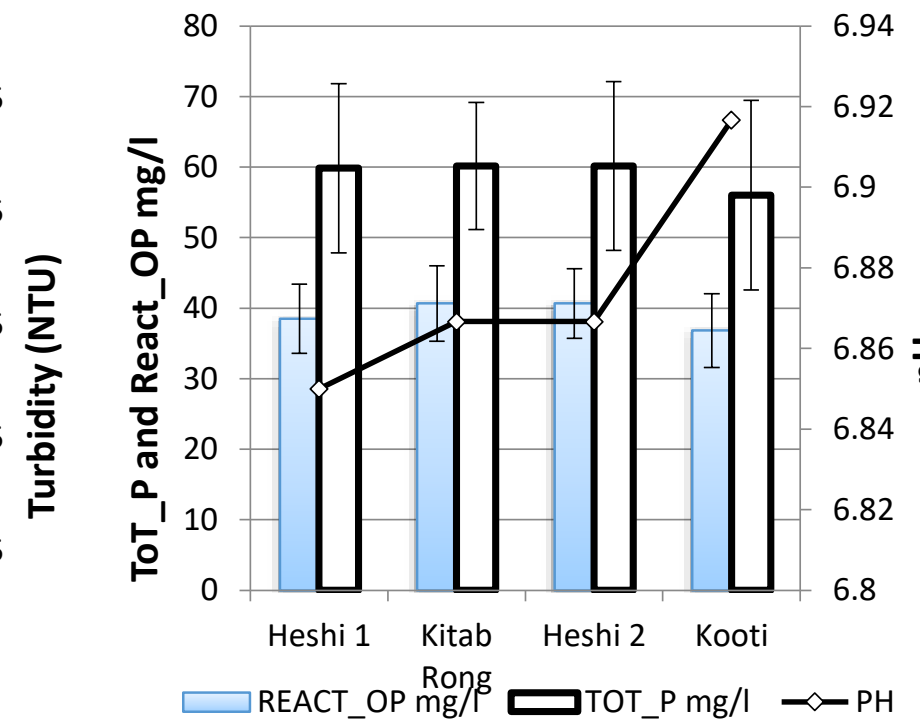

Fig.4: Variation in chemical parameters of all four springs eye

In time period of this study, there were significant variations in temperature measured in all the four springs (Heshi spring 1, Heshi spring 2, Kitaab Rong spring, and Kooti spring) and its various distribution systems. The temperature was in a range of $13^{\circ} \mathrm{C}-22^{\circ} \mathrm{C}$. The minimum temperature $13^{\circ} \mathrm{C}$ was observed in Heshi spring and the temperature in rest of springs didn't differ much. Maximum temperature $22^{\circ} \mathrm{C}$ was observed in distribution system mid (tap). The low temperature may be due to high altitude of spring eye 2637 meter above sea level and high temperature may be due to increased atmospheric temperature at the mid of distribution system. Physicochemical parameter of four springsTDS was in a range of 164-513 with mean 272 \pm 82.681 , The remarkable observation of the study was the level of total dissolved solids (TDS) in Kooti spring where it exceeds WHO permissible limit prescribed for drinking water. Excluding Kooti spring all samples fall in the limits set by WHO [11]. Drinking water with high level of TDS may lead to a number of diseases which are not water-borne but as a result of excess salts [12].Electric Conductivitywas in a range of 306-547 with mean 394.75 \pm 56.78 . The electrical conductivity displayed variation in different water samples. It was in a range of minimum $122 \mu \mathrm{S} / \mathrm{cm}$ to a maximum of $600 \mu \mathrm{S} / \mathrm{cm}$. None of the samples cross permissible limit of WHO standards of drinking water. The electric conductivity showed fluctuation possibly because of inorganic fertilizer inputs and from domestic sewage contamination [13] or might be as a result of bicarbonate and calcium ions present in the rocks there. 
Whereas turbiditywas observed in a range 0.02-0.29 with mean value $0.15 \pm 0.0561$. The minimum value measured was $0.02 \mathrm{NTU}$ in the Heshi spring 1 eye. While the maximum value $1.99 \mathrm{NTU}$ was observed in the inlet of water reservoir. None of the values exceed permissible limit $<5$ NTU of WHO standards.

Reactive Orthophosphate was in range of 28-51 with mean $38 \pm 4.8132$. The amount of reactive ortho phosphate was in a range of $26 \mathrm{mg} / \mathrm{l}$ to $59 \mathrm{mg} / \mathrm{L}$. The maximum of $59 \mathrm{mg} / \mathrm{L}$ was found in end point of distribution network. This value crosses the standard limit of WHO.While total phosphorous was observed in a range of 23-120 with mean $41.25 \pm 6.1016$. The amount of total phosphorous showed great fluctuation. It was in a range of minimum $23 \mathrm{~m} / \mathrm{L}$ to maximum of $120 \mathrm{mg} / \mathrm{L}$. The maximum amount was observed again in end point of distribution system while minimum in Kooti spring. The results showed that all the water samples exceed the prescribed limit of WHO standards $5 \mathrm{mg} / \mathrm{L}$ of total phosphorous.
$\mathrm{pH}$ was observed in a range of 6.2-7.1 with mean $6.425 \pm 0.1031$. The minimum $\mathrm{pH}$ value was observed in the Heshi spring 1 where it was 6.2 while maximum value 7.1 was observed in mid and end point of distribution network. Heshi spring 1 and Kooti spring have $\mathrm{pH}$ value below the permissible limit as per WHO drinking water standards rest of the springs and all the samples from distribution system fell within the World Health Organization's limit. These findings were supported by [13] who conducted a study on water used for drinking and swimming purposes in Abeokuta, Nigeria stated that the $\mathrm{pH}$ was in a range of 6.8-7.3. while total phosphorous was observed in a range of 23-120 with mean $41.25 \pm 6.1016$. The amount of total phosphorous showed great fluctuation. It was in a range of minimum $23 \mathrm{~m} / \mathrm{L}$ to maximum of $120 \mathrm{mg} / \mathrm{L}$. The maximum amount was observed again in end point of distribution system while minimum in Kooti spring. The results showed that all the water samples exceed the prescribed limit of WHO standards $5 \mathrm{mg} / \mathrm{L}$ of total phosphorous.

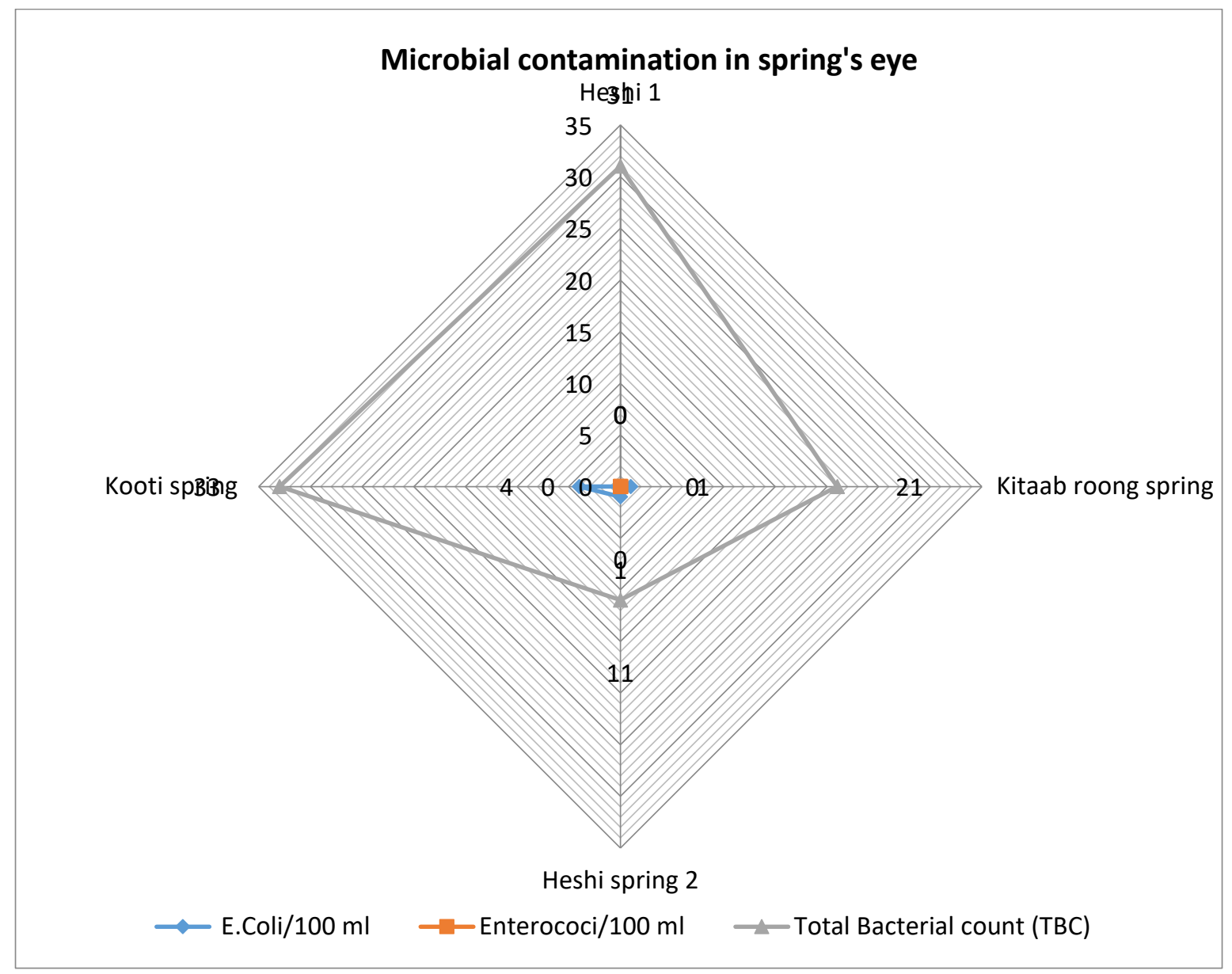

Fig.5: Variation among all microbial parameters in each spring eye

The bacteriological assessment of water establishes the potability of water. The permissible limit of bacteria set by WHO for drinking water quality is $0 \mathrm{CFU} / 100 \mathrm{ml}$. All the samples of our study were bacterially contaminated.
In the all four spring sources no enterococci were observed and three sources were contaminated with $E$. coli. All points of distribution system were highly contaminated with both (Enterococci and E. coli). The 
total bacterial count was in a range of $11 \mathrm{CFU} / 100 \mathrm{ml}$ to 83 $\mathrm{CFU} / 100 \mathrm{ml}$. All the findings revealed that all the samples were contaminated with bacterial population and not fit for drinking purpose according to WHO recommendations. Coliform bacteria are prime indicator for faecal contamination of water [15]; [16]. This finding is in accordance with the results of [15] who under took a study on underground water of Gwailor city, India where almost all samples were bacterially contaminated and cross the permissible limit.

\section{CONCLUSION}

The present study revealed that the quality of water in all four springs i.e. Heshi spring 1, Kitaab Roong spring, Heshi spring 2, and Kooti spring are physically fit for consumption while they exceed the chemical limits (Reactive orthophosphate \& Total phosphorous) as per WHO standards. In terms of microbial point of view the springs were contaminated with $E$. coli while no enterococci were found in the spring eye. Although springs contain safe edible drinking water but there is no pipeline distribution system that's why they are faecally contaminated. Shepherds take their animals to the meadows so they contaminate water faecally as springs are not protected.

\section{REFERENCES}

[1] Karrar. M., \& Affan Iqba. A report on Gilgit City. Urban Research\&Design Cell (URDC), Department of Architecture and Planning, City Campus NED University of Engineering and Technology, Maulana Din Mohammed Wafai Road, Behind DJ. Science College, Karachi, 2011.

[2] Ecological Society of America. Water in changing world. Issues in Ecology.9:4.

[3] Munair, S. (2003). Protection of water resources in Northern Punjab, Water-A vital source of life, International year of fresh water.The United Nation System in Pakistan,2001.

[4] Larry, W. Survey of Gross Alpha Radioactivity in Bore Hole and Well Water in Sokoto City NorthWestern Nigeria.Nig. J. Basic Appl. Sci. 21(1):2026, 2006. Chemical properties of water samples from Manipur River system, India, J.Appi.Sci.Environ.14 (4); 8589, 2010.

[6] Simpi, B., Hiremath, S.M., Murthy, K., Chandrashekarappa, A.N., Pat., Puttiah, E.T. Analysis of Water Quality Using PhysicoChemicalpARAMETERS Hosahalli Tank in
Shimoga District, Karnataka, India. Glo. J. Sci. Front. Res.11, 30-34,2011.

[7] Adewuyi, G.O., Opasina, M.A. Physicochemical and Heavy Metals Assessments of Leachates from Aspirin Abandoned Dumpsite in Ibadan City, Nigeria.E-J. Of Chemist, 2010.

[8] Odeyemi, A.T., Akinjogunla, O.J \& OJO, M.A.,. Bacteriological,Physicochemical and Mineral Studies of Water Samples from Artesian bore-hole, spring and Hand dug well located at Oke-Osun, Ikere-Ekiti, Nigeria. Scholars Research Library, 94108, 2011.

[9] Tartari, G.A. \& R. Mosello. Analytical methods and quality control in the chemical laboratory of the Institute of Hydrobiology of the Italian National Research Council. DocumentaIst. Ital. Idrobiol., 60: 160 pp, (1997).

[10] APHA-AWWA-WEF. Standard Methods for the Examination of Water and Wastewater.20th ed. Washington DC: American Public Health Association, 1999.

[11]WHO. 3rd edition, I World Health Organization,2008.

[12] Sabata B.C. AND Nayar M.P. River pollution in India: A case study of Ganga River, 33,1995.

[13] Kumar Pban., Dushenkov. V., Motto H, R. Phytoextraction: The use ofPlants to remove heavy metals from soils. Environ. Sci. Technol. 29(5):1232-1238,1996.

[14] SHITTU, O.B., OLAITAN, J.O. AND AMUSA, T.S. Wetzel R.G., Limology, W. B., Saunders Co., Philadelphia, USA, 743(1975) Physicochemical and Bacteriological Analyses of Water Used for Drinking and Swimming Purposes in Abeokuta, Nigeria. Afr. J. Biomed. Res., 11: 285-290, 2008.

[15] Parihar V.L., Sharma M.S. AND SHARMA L.L. Utility of bacteriological parameters for assessing best use and trophic status of seasonal water: A case study from Udaipur, Rjasthan. Poll. Res., 22(2),163167, 2003.

[16] Mohan. D., Gaur. A and Chodhary. D. Study of limnology and microbiology of NayaTalab, Jodhpur, Rajasthan, Proceed. Nat. Symp. onLimnology, 6468, 2007. 